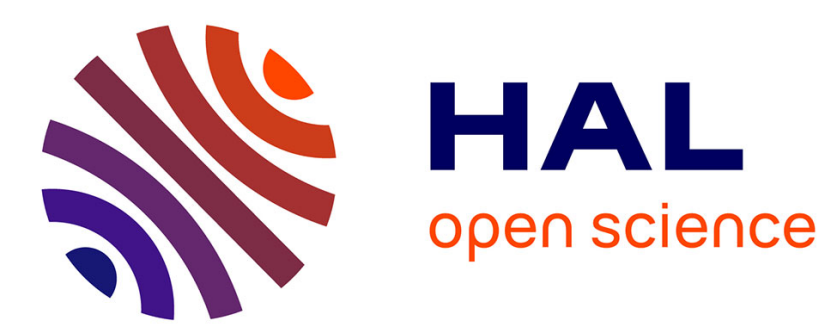

\title{
The Effect of Receiving Supplementary UI Benefits on Unemployment Duration
}

T. Kyyra, Pierpaolo Parrotta, M. Rosholm

\section{To cite this version:}

T. Kyyra, Pierpaolo Parrotta, M. Rosholm. The Effect of Receiving Supplementary UI Benefits on Unemployment Duration. Labour Economics, 2013, 21, pp.122-133. 10.1016/j.labeco.2013.02.002 . hal-01514533

\section{HAL Id: hal-01514533 \\ https://hal.science/hal-01514533}

Submitted on 14 Jun 2018

HAL is a multi-disciplinary open access archive for the deposit and dissemination of scientific research documents, whether they are published or not. The documents may come from teaching and research institutions in France or abroad, or from public or private research centers.
L'archive ouverte pluridisciplinaire HAL, est destinée au dépôt et à la diffusion de documents scientifiques de niveau recherche, publiés ou non, émanant des établissements d'enseignement et de recherche français ou étrangers, des laboratoires publics ou privés. 


\title{
The Effect of Receiving Supplementary UI Benefits on Unemployment Duration
}

\author{
Tomi Kyyrä, Pierpaolo Parrotta ${ }^{\dagger} \&$ Michael Rosholm
}

11th January 2013

\begin{abstract}
We consider the consequences of working part-time and receiving supplementary benefits for part-time unemployment in the Danish labour market. Following the timing-of-events approach we estimate causal effects of part-time work with supplementary benefits on the hazard rate out of unemployment insurance benefit receipt. We find evidence of a negative in-treatment effect and a positive post-treatment effect, both of which vary across different groups of individuals. The resulting net effect on the expected unemployment duration is positive for some groups (e.g. married women) and negative for others (e.g. young workers).
\end{abstract}

JEL Classification: C41, J65

Keywords: Unemployment benefits, part-time work, lock-in effect, treatment effect, duration analysis.

\footnotetext{
${ }^{*}$ Corresponding author at: Government Institute for Economic Research, Helsinki, and Department of Economics and Business, Aarhus University, and IZA. Email address: tomi.kyyra@vatt.fi.

${ }^{\dagger}$ Department of Economics and Business, Aarhus University, and Department of Economics, University of Lausanne.

${ }^{\ddagger}$ Department of Economics and Business, Aarhus University, CAFE, and IZA.
} 


\section{Introduction}

Flexibility in labour markets has become a key issue in Europe in the wake of persistently high unemployment rates, and the current economic crisis with large increases in unemployment rates in most European countries has intensified the debate further.

A number of strategies have been pursued in order to increase labour market flexibility. Some countries, in particular the Nordic countries, have adopted so-called Flexicurity systems, where low hiring and firing costs are combined with generous social security schemes to increase flexibility directly. In other countries, temporary work contracts are used along with stringent employment protection rules for regular employees, aiming at increasing flexibility in inherently inflexible labour markets. Interestingly, in both types of regimes, the same types of policy instruments are used, e.g. active labour market policies and some forms of subsidized temporary or reduced work arrangements. These may take the form of supplementary unemployment benefits, which is the topic of this paper, while they also take the form of explicit temporary employment contracts. Thus, several forms of supplementary or partial unemployment benefits have emerged in almost all European countries and in North America, aimed at making it more attractive for job seekers without any job to accept part-time work, and hence increase overall employment and production.

Supplementary benefits are specifically aimed at supplementing the income of parttime workers who are looking for full-time work and to improve the unemployed workers' incentives to accept part-time employment. However, the presence of the supplementary unemployment benefits may produce adverse selection into such schemes and may in some cases facilitate forms of moral hazard behaviour. Specifically, such benefits could discourage recipients from searching for regular full-time employment due to the relatively high replacement rates and/or prolonged benefit periods associated with working part-time and receiving supplementary benefits. Thus, the potential for both positive and negative consequences of supplementary benefit schemes imply that the desirability of such a policy is an empirical question, which needs to be answered empirically.

In this paper, we study supplementary unemployment insurance (UI) benefits and the role they play in Denmark. The empirical analysis is conducted on a flow sample of workers who became unemployed in 1999-2006 and qualified for regular UI benefits. Some of these workers eventually entered part-time employment and received supplementary UI benefits for the rest of time. We consider such a period as part of the spell of compensated unemployment. This is reasonable because supplementary UI benefit recipients are supposed to be looking for full-time work. We seek to answer the counterfactual question 'what would have happened to these workers had they not received supplementary UI benefits and parttime employment but instead continued in full-time unemployment'. Thus, we evaluate the effect of working part-time (say, $x$ hours per week) and receiving supplementary UI benefits for the rest, that is, $37-x$ hours, since 37 hours correspond to full-time employment. Hence, we seek to answer whether working combined with supplementary UI benefits may act as a 'stepping stone' to full-time employment for unemployed workers. In doing so, we 
ignore any general equilibrium effects that might occur, thus implicitly assuming that the implied increase in labour supply translates fully into increasing employment in the longer run.

In the econometric analysis, the outcome variable is the expected time until the job applicant leaves compensated unemployment, and thereby completes his or her compensated search for full-time work. We model this duration outcome by specifying a hazard model for transitions out of UI benefits. The receipt of supplementary UI benefits is then viewed as a "treatment" occurring during the unemployment spell, which possibly affects total unemployment duration (through an impact on the exit rate from unemployment). We distinguish between the effect on the hazard rate out of unemployment during the weeks when supplementary benefits are actually received (which we call the in-treatment effect) and the effect following the completion of the supplementary benefit period (which we refer to as the post-treatment effect).

To deal with the endogeneity of the receipt of supplementary benefits, we specify another hazard model for transitions from regular UI benefits to supplementary UI benefits (from full-time unemployment to part-time employment with supplementary UI benefit receipt). This produces a bivariate duration model, where the two hazard functions are related via observed as well as unobserved characteristics. By assuming random variation in the timing of the receipt of supplementary UI benefits, the causal effect of part-time work with supplementary UI benefits can be nonparametrically identified from the selection effect without imposing any exclusion restrictions. This way of modelling causal effects in duration models has become known as the 'timing-of-events' approach (Abbring and Van den Berg, 2003).

We find evidence of a significant in-treatment effect: being on supplementary UI benefits lowers the transition rate out of unemployment. In addition, we find a positive posttreatment effect of having received supplementary UI benefits. We proceed to estimating heterogeneous effects for sub-groups of unemployed workers, and calculate the effect on the expected remaining unemployment duration for those different groups and also describe the distribution of effects. For example, we find that receipt of supplementary UI benefits has positive implications for young workers: part-time work combined with supplementary benefits reduces their expected remaining time in unemployment. Hence, making supplementary UI benefits available to young workers may be an interesting labour market policy instrument, in the sense that part-time work can provide a stepping stone to regular employment for them. This may be important policy information, as the current crisis has seen dramatic increases especially in youth unemployment rates.

The structure of the paper is as follows: the next section briefly summarizes the debate on the role of part-time and temporary jobs; the 3rd section briefly outlines the Danish regulatory system of supplementary UI benefits; the 4th section provides details on the data set and some descriptive statistics. The econometric model is outlined in the 5th section, and the results are discussed in the 6th section. Section 7 contains a conclusion, a brief discussion of costs and benefits, and some policy considerations. 


\section{Literature Background}

Part-time and temporary jobs in the labour market are part of what is usually labelled as 'atypical employment'. These jobs are often occupied by individuals who have difficulties obtaining regular full-time employment, while for others having a part-time job is simply a voluntary choice. The supplementary UI benefit scheme is naturally aimed at the first group of individuals.

\subsection{The Debate on Temporary and Part-Time Employment}

Some researchers have argued that part-time jobs (and other atypical jobs) may act as stepping stones towards regular and more stable work. First of all, in some cases temporary and part-time jobs can represent the only way of escaping (full-time) unemployment. Secondly, those jobs can be used by employers as useful screening (or signaling) devices for permanent job positions (Storrie, 2002; Houseman et al. 2003). Thirdly, they can provide valuable skills, work experience and in some cases facilitate the acquisition of specific human capital. Finally, they may induce individuals to enlarge their job network (labour market contacts) and consequently increase their possibilities for obtaining full-time employment.

On the other hand, there may be disadvantages of promoting temporary and part-time jobs: they may just postpone the (full-time) unemployment experience (Hartman et al. 2010) and thus lengthen the time until regular employment. Part-time employment is often associated with uncertainty about future income and working hours, and consequently, it is difficult to make investment and savings decisions, to obtain credit, make child care arrangements and so on. The high concentration of low-skilled and less educated workers in part-time jobs may indicate that some of these jobs are dead-ends, since firms may not be planning to hire these workers on full-time basis, thus limiting their possibilities to improve upon their future situation (Heinrich et al. 2005). Consistent with this hypothesis, Autor and Houseman (2010) find that, while temporary jobs reduce subsequent earnings and job stability, job placements with direct-hire employers work in the opposite direction. According to Røed and Westlie (2012), part-time employment has only minor effects on exit rates to other forms of public income support and education. Graaf-Zijl et al. (2011) find evidence that temporary jobs shorten unemployment duration but seem not to increase the probability of getting a regular job. However, their results indicate that regular jobs following temporary employment pay higher wages than regular jobs found directly from unemployment. Cockx and Picchio (2012) find that short-term (temporary) jobs may act as stepping stones to permanent employment for some groups, while for others (the well educated in particular), there were unfavourable effects.

It is typically argued that temporary and part-time employment lower costs associated with layoffs and labour hoarding, and reduce cyclical swings in labour productivity as firms often shed workers quickly in downturn periods. However, the promotion of temporary and part-time jobs as a way of increasing the degree of labour market flexibility is believed 
by some authors to be undesirable, especially in countries where employment protection legislation is not particularly strong and flexibility is already high (such as in Denmark). As pointed out by Booth et al. (2002), individuals lacking regular jobs for a long period or falling several times into the temporary or part-time work regime may irredeemably damage their career prospects and long-term earnings opportunities. Conversely, Jahn and Rosholm (2010) find that employment in temporary help agencies in Denmark reduces the time to full-time employment for unemployed workers, increases subsequent wages and tends to lengthen subsequent employment spells. They also show that temporary agency employment is most effective when the local unemployment rate is low, suggesting that employers may use temporary-help agencies as a relatively cheap screening device when there is labour shortage.

\subsection{The Role of Supplementary UI Benefits}

A number of studies have discussed the role of public policy instruments to compensate and possibly overcome the adverse effects related to temporary and part-time jobs (Rasmussen et al. 2004; Møller and Lind, 2000). Specifically, supplementary UI benefits provide financial incentives to accept part-time jobs that may not be acceptable without subsidies. However, the availability of such benefits may induce forms of adverse selection or fraud when persons who would never be interested in full-time employment suddenly qualify for them - and moral hazard behaviour - an individual receiving supplementary UI benefits has a financial incentive to intentionally delay getting a full-time job by searching less intensively than what is optimal from society's point of view. On the other hand, an intensive active labour market policy may actually induce unemployed individuals to search actively for employment (Rosholm, 2008), so to the extent that the availability for full-time employment of supplementary UI benefit recipients can be tested, the adverse selection and moral hazard risks of a generous income compensation regime (such as the Danish Flexicurity model) may be overcome by intensive monitoring and sanction policies, see also Svarer (2011).

Only a few studies treat the role of supplementary UI benefits in search behaviour and the nature of subsequent employment. The first study we found is Munts (1970), which analyzes whether supplementary benefits encourage or discourage search for regular work. He provides evidence on workers receiving partial benefits in Wisconsin and finds that they adjust their part-time work to gain from combined earnings and benefits. Holen and Horowitz (1974) confirm and strengthen the conclusions reached by Munts.

McCall (1996) studies whether the level of the earnings disregard influences an UI recipient's job search behaviour. ${ }^{1}$ The analysis is performed on U.S. data, where the amount of earnings disregarded varies across states and within states over time. Developing and using a continuous-time job search model, McCall shows that an increase in the level of earnings disregard generally increases both the part-time and overall re-employment

\footnotetext{
${ }^{1}$ The level of disregard is the earnings threshold above which a recipient cannot receive the full amount of benefits but just a part of it (as benefits are reduced on a dollar-for-dollar basis after the threshold).
} 
hazards. Specifically, an increase in the level of disregard causes higher transition rates from full-time unemployment to part-time employment during the first three months of unemployment.

Moreover, McCall (1997), using a Canadian Survey, points out that whereas recipients not qualified for partial unemployment benefits are characterized by increasing parttime and full-time re-employment hazard as benefits are exhausted, those qualified for partial benefits show increasing full-time re-employment hazard but decreasing part-time re-employment hazard. He states that the discrepancy occurs because part-time jobs are indirectly subsidized and then the value of the subsidy for the former category decreases as benefits are exhausted. In addition, he finds that women have longer joblessness duration and higher propensity to be re-employed as part-timers than men.

Munts (1970), Holen and Horowitz (1974) and McCall $(1996,1997)$ thus provide evidence that availability of partial unemployment benefits induces the unemployed to take up part-time jobs that allow them to claim partial benefits. However, these studies are not informative on whether occupying such jobs subsequently helps unemployed workers find regular full-time jobs and hence reduce the overall duration of unemployment benefit receipt, which is the topic of the present study.

Arguably, the most relevant theoretical framework for thinking about subsidized parttime unemployment is the paper by Ek and Holmlund (2011). They develop a search and matching model to study the design of optimal unemployment insurance in an economy with full and part-time unemployment. They construct an economy with two sectors (industries), where full-time jobs are offered in one sector and part-time jobs in the other sector: unemployed workers search for both part-time and full-time jobs (preferring the latter but willing to consider the former as a stepping stone), while part-time workers search only for full-time employment. Thus, the provision of more generous benefits to part-timers increases transitions from unemployment to part-time employment but reduces transitions into full-time jobs at the same time. Their results suggest that unemployment insurance benefits should optimally have limited duration for full and part-time unemployment benefits.

We will briefly digress from the pure literature review here to discuss how the results in Ek and Holmlund (2011) may be informative with respect to our work. Since leisure provides utility, taking a part-time job with part-time UI benefits may lead to dramatically low search intensities for individuals with high values of leisure relative to consumption, leading to a lock-in effect of part-time jobs, while for others with lower preferences for leisure, this effect may be more modest. This may lead to heterogeneous impacts for individuals with different preferences for leisure due to, say, age, marital status, etc. Another source of heterogeneity may be via search effectiveness, which may also differ between different groups, depending on, say, knowledge of local labour markets. Finally, taking a part-time job may signal willingness to work to potential full-time employers, and this may be more important to individuals with less labour market experience, such as young workers and Non-Western immigrant workers. 
The model of Ek and Holmlund (2011) does not allow for past part-time (un)employment affecting the current transition rate from full-time unemployment to full-time employment, which will turn out to be an important feature in our empirical work. However, it is fairly straightforward in terms of their model to think of channels through which having held a part-time job may raise the transition rate from full-time unemployment to full-time employment, for example via network effects (some of your previous colleagues in the part-time job may have moved on to full-time employment and may recommend you), via increases in human capital obtained in the part-time job that is also rewarded in full-time employment, or via signalling effects as discussed above.

The empirical paper most closely related to our study is Kyyrä (2010), which examines the effects of the receipt of supplementary UI benefits on the exit rate from unemployment to regular employment in the Finnish labour market. Using a timing-of-events duration model, he finds a noticeable increase in the exit rate following receipt of supplementary benefits but no evidence of negative in-treatment effects. Hence, working combined with supplementary UI benefits reduces the expected duration until regular employment. The Finnish study has a relatively small number of observations on supplementary UI benefit recipients, which hampered attempts to detect heterogeneity in the effects across individuals. In the present study, impact heterogeneity will play a central role.

Thus, the supplementary UI benefits seem to produce positive as well as negative effects, depending on the specific circumstances and incentives facing the individuals. Hence, rules and regulations concerning supplementary benefits and part-time work can significantly influence the effort spent on job search and/or the level of reservation wages for regular employment. From the recipient's point of view, the opportunity cost associated with the provision of supplementary benefits depends crucially on the willingness to find a regular job and varies over the receiving period.

\section{Supplementary UI Benefits in Denmark}

As in most countries, in Denmark supplementary UI benefits are supplements to the weekly earned income for persons working part-time. The minimum requirement to receive supplementary benefits is a) membership of an unemployment insurance fund, and b) part-time work during a week. Obviously, workers have to meet several other requirements in order to be entitled to supplementary UI benefits. Individuals receiving UI benefits have been working and contributing insurance payments to an UI fund in order to be eligible for UI benefits at all. A full-time insured UI fund member is entitled to supplementary UI benefits if her working hours are reduced by more than 7.4 hours in a week. Thus if she works 29.6 hours or more in a week, she is not entitled to supplementary UI benefits. A worker having only part-time unemployment insurance is entitled to receive supplementary UI benefits if his working hours are reduced by more than $20 \%$ of his average weekly working hours before unemployment.

The exhaustion of the entitlement period for supplementary UI benefits depends on 
whether an individual has a part-time job with or without terms of notice. In the former case, the worker can at most receive supplementary UI benefits for 52 weeks. When she has done so, the right to receive supplementary UI benefits is ceased until she has worked more than 30 hours a week for 26 weeks during the last 12 months.

When the part-time job has no terms of notice, the right to receive supplementary benefits is not limited to 52 weeks but instead to four years. After this period one may receive benefits for an additional four years by working full-time for 52 weeks within three years. Finally, with or without terms of notice, supplementary UI benefits can at maximum be received for four years within a six-year period. ${ }^{2}$

In 2006 124,947 persons received supplementary UI benefits at some point: ${ }^{3}$ this number corresponds to 11,738 full-time-full-year equivalent (FTE) unemployed workers. The number of recipients of supplementary UI benefits, measured as FTE unemployed, went up from 1999 to 2004. In 1999 there were approximately 11,500 FTE supplementary UI benefit recipients. This number peaked in 2004 with more than 14,000 recipients. During 2005 and 2006 the number fell to the same level as in 2001. The trend concerning the number of supplementary UI benefit recipients has not followed the unemployment rate. Unemployment fell from 1999, where it was just above 5\%, to 2002, increased until 2004 and has fallen again since then. In 2006, the unemployment rate was just below $4 \%$. Over the same period, the ratio of FTE supplementary UI benefit receivers to the number of all unemployed has grown steadily.

\section{Data and Descriptive Statistics}

The data used here is an $8 \%$ random sample of the Danish population entering unemployment in the period covering the years 1999-2006, and who were insured against full-time unemployment. ${ }^{4}$ The data is based on administrative registers used for administering UI benefit payments, assignments of individuals to active labour market programs etc., and is made available to us by the Danish Central Labour Market Authority (Arbejdsmarkedsstyrelsen). The data is thus considered highly reliable.

Our sample consists of 74,571 individuals experiencing a total of 240,675 unemployment spells, defined below. One third of the individuals experienced only a single spell of unemployment while two thirds experienced no more than 3 spells. Less than $3 \%$ of the individuals experienced more than 9 spells.

In the econometric analysis below, we will treat supplementary UI benefit receipt as the treatment, and the length of the time from entry into open unemployment until exit from unemployment benefits as the outcome variable. We refer to this period of time as

\footnotetext{
${ }^{2}$ The rules are tremendously more complicated than explained here, and there are numerous exceptions. In the empirical section we will limit ourselves to the individuals to whom the above rules apply.

${ }^{3}$ One reason for this large number is that a person who becomes unemployed or leaves unemployment in the middle of a week will receive supplementary benefits for the remainder of that week. This is just a consequence of the fact that UI benefits are calculated on a weekly basis in Denmark.

${ }^{4}$ Close to $80 \%$ of the Danish labour force are members of an UI fund, while the remainder are eligible for social assistance, which is lower, should they become unemployed.
} 
an unemployment spell. We shall start by defining our treatment and outcome variables in terms of our data.

The outcome variable: The dependent variable in the study is unemployment duration measured in weeks. An unemployment spell is defined as a sequence of weeks during which a person receives either full-time UI benefits, supplementary UI benefits, participates in some type of active labour market program, or receives a related income transfer (such as sickness payments while unemployed, holiday payments while unemployed etc.). That is, part-time employment coupled with supplementary UI benefits is here treated as part of the unemployment spell in order to enable the counterfactual analysis. The unemployment spell is completed when the individual no longer receives any kind of public income transfer related to unemployment. Since the individuals in our sample are all eligible for UI benefits, the only likely reasons for not receiving UI benefits are that you found employment, your benefit eligibility expired, you went into education or out of the labour force on some other kind of income transfer. UI benefit eligibility expires after 4 years, and in this period less than $0.5 \%$ of the inflow cohort experience such a long unemployment spell. Unemployment spells continuing until the end of the sample period (the 24 th week of 2007) are treated as independently right-censored observations (less than $2 \%$ of all spells).

The treatment variables: An unemployed person is classified as a recipient of supplementary UI benefits in a given week

1. if he or she was not participating in any kind of active labour market programs, and

2. if the reduction in benefits corresponds to more than 7.4 hours (implying part-time work of 29.6 hours or less).

Single weeks of supplementary UI benefit receipt that lie during the first or last week of an unemployment spell are not defined as a treatment week. The reason is that such one-week periods are probably due to the timing of unemployment entry or exit during the week. ${ }^{5}$

There are two treatment variables:

1. a time-varying indicator for currently working part-time and receiving supplementary UI benefits (the in-treatment variable), and

2. a time-varying indicator for having received supplementary UI benefits earlier during the current unemployment spell (the post-treatment variable).

Since the implemented econometric model cannot deal with selection at time zero, we further restrict our sample to those who initially received full-time UI benefits by excluding 6,605 spells that begin with receipt of supplementary UI benefits (for a period longer than one week), leaving 234,070 unemployment spells that are used in the analysis. The

\footnotetext{
${ }^{5}$ Say, if the job is lost on Wednesday, then the UI benefits for that week are reduced by 2 working days, corresponding to 14 hours. When it comes to exits from unemployment, our definition implies that some treatments that are immediately successful are ignored in the sense that first-week transitions out of supplementary UI are ignored. In this sense, our treatment effects are conservative.
} 
exclusion of these 6,605 unemployment spells does not matter much to our results (see Section 6.6).

As control variables, we have access to background information concerning family status (married or not), gender, age (6 categories), ethnic origin (5 groups), current area of residence (14 counties), and UI fund membership categories (9 occupation/industry-related funds). We also include a few variables describing past labour market history, specifically, 3 variables measuring the fraction of time in which the individual received any public income transfers, not just those related to unemployment, in each of the past 3 years, a variable measuring the share of weeks in the past year that an individual was unemployed, and another variable for the share of weeks the individual received supplementary UI benefits in the past year. All these covariates are measured at the beginning of the unemployment spell and will be treated as time-invariant regressors, which are fixed for each single spell but can vary over different spells for the same person. In addition, we include time-varying indicators for each quarter of the observation period (a total of 33 dummy variables) to control for changing labor market conditions.

Table 1 shows descriptive statistics when the sample of unemployment spells has been split into two groups - those who did and those who did not receive supplementary UI benefits during their unemployment spell. Descriptive statistics for the entire population are not provided since the chosen random sample is representative. Note that the observations refer to unemployment spells, not to individuals.

Of the 234,070 unemployment spells, 43,392 spells (19\%) involve receipt of supplementary UI benefits. These spells are much longer on average (48 vs. 16 weeks) than unemployment spells without a treatment. The average time until the first receipt of supplementary UI benefits is 15 weeks (not reported in the table). Among those who received supplementary UI benefits, the mean duration of supplementary UI benefit periods is 3.6 weeks and the average number of such periods, separated by full-time unemployment, during a given unemployment spell is 3.3 (not shown in the table). As a result, the average number of weeks on supplementary UI benefits during the unemployment spell is about 12 weeks.

- Table 1 about here -

Women (married and singles) are more likely to experience periods on supplementary UI benefits during unemployment than men. This may have at least three explanations; first, it might just reflect that women on average are unemployed for longer periods of time than men, and therefore they are also more likely to experience a period of supplementary UI benefit receipt. Second, it may be because they have a stronger preference for working part-time (having higher preferences for leisure relative to consumption), and third, it may be the case that the employers of women have higher demands for part-time workers and hence push women into these schemes.

The average age among those flowing into unemployment is about 40, and supplementary UI benefit recipients are slightly older than non-recipients. Among UI funds, it is 
seen that those that are over-represented in supplementary UI benefits are mainly in the 'white-collar' and 'others' UI funds. Immigrants and their descendants do not appear to be either over- or under-represented among supplementary UI benefit recipients. Finally, we observe that those receiving supplementary UI benefits were more dependent on public income transfers in the 52 weeks before becoming unemployed, but they hardly differ in terms of time spent in unemployment ( $27 \%$ vs. $24 \%$ ). Both groups spent only a little time on supplementary UI benefits in the year before the current spell of unemployment ( $5 \%$ and $2 \%)$.

\section{Econometric Model}

The econometric analysis aims at estimating the causal effect of receiving supplementary UI benefits on the duration of an unemployment spell as defined above. This is done by using the timing-of-events approach formalized by Abbring and Van den Berg (2003). Exploiting variation in the observed moment of transition from full-time unemployment to part-time unemployment with supplementary UI benefits, this approach is ideal for separating selection from causal effects in a duration model context. Furthermore, it allows us to estimate time-varying as well as heterogeneous treatment effects (where the heterogeneity is with respect to observed characteristics) of receiving supplementary UI benefits.

As mentioned above, we consider receipt of supplementary UI benefits to be the treatment, which is undertaken during a spell of unemployment, and we then want to estimate the effect of this treatment on the exit rate from unemployment both during and after the receipt of the treatment.

Let $T_{u}$ be a continuous random variable measuring the time from becoming unemployed until exit from unemployment benefits. The hazard rate out of unemployment is assumed to be of the Mixed Proportional Hazard (MPH) form, that is

$$
\theta_{u}\left(t \mid x, \tau, d_{1}(t), d_{2}(t), v_{u}\right)=\lambda_{u}(t) \exp \left[x \beta_{u}+z(t+\tau) \delta_{u}+d_{1}(t) \gamma_{1}+d_{2}(t) \gamma_{2}+v_{u}\right]
$$

where $t$ denotes the elapsed duration of unemployment and $\tau$ denotes the calendar time at the beginning of the unemployment spell. The hazard function is defined as the product of a baseline hazard, $\lambda_{u}(t)$, depending on the elapsed unemployment duration, and a scaling function, depending on observed background characteristics, $x$, calender-time effects captured by a vector of 33 time-varying year-quarter dummies, $z(t+\tau)$, unobserved characteristics $v_{u}$, and the time-varying indicators for being in treatment, $d_{1}(t)$ (i.e. receiving supplementary benefits at time $t$ ), and for having received treatment, $d_{2}(t)$ (i.e. having received supplementary benefits before $t$ but is not receiving at $t$ ). The coefficients $\gamma_{1}$ and $\gamma_{2}$ thus capture the in-treatment and post-treatment effects of the receipt of supplementary UI benefits on the hazard rate out of unemployment, respectively. We also estimate a model, where the treatment indicators $d_{1}(t)$ and $d_{2}(t)$ are interacted with the explanatory 
variables, $x$, in order to test for the presence of heterogeneous effects.

In order to allow an interpretation of $\gamma_{1}$ and $\gamma_{2}$ as causal effects, we have to take into account the potential endogeneity of receipt of supplementary UI benefits. Let $T_{p}$ denote the time from becoming unemployed until the person finds part-time employment and thus begins receiving supplementary UI benefits. Note that, by construction, $T_{u} \geq T_{p}$, since we consider periods with receipt of supplementary UI benefits to be part of the unemployment spell. Following the notation used above and specifying once again a MPH function, the transition rate into supplementary UI benefits is specified as

$$
\theta_{p}\left(t \mid x, \tau, v_{p}\right)=\lambda_{p}(t) \exp \left[x \beta_{p}+z(t+\tau) \delta_{p}+v_{p}\right]
$$

The unobserved stochastic variables $v_{u}$ and $v_{p}$ are allowed to be correlated, which implies a correction for the potential endogeneity of the treatment status. Obviously, one might also consider whether not only the timing of the treatment, but also its duration, are endogenous variables. We make the assumption here that all selection can be characterized by the equation describing the hazard rate into supplementary UI benefits, $\theta_{p}\left(t \mid x, \tau, v_{p}\right)$, and thus ignore any additional endogeneity of the treatment duration.

Note that, conditional on the underlying MPH model, the random variation in the timing of the treatment identifies the causal effect of the treatment under the assumption that unobserved characteristics are time-invariant and properly captured by the discrete distribution. Abbring and Van den Berg (2003) show that, due to random variation in the timing of treatment, no exclusion restriction is necessary to identify the parameters of the model nonparametrically. The only assumption necessary, beyond the assumption of mixed proportional hazards, is one of no-anticipation, that is, the individual is not supposed to know in advance the exact starting date of the part-time job, only its probability distribution. In reality, this assumption is of course always violated, but as long as the individual does not know the exact starting date too long in advance, this is generally not perceived as a large problem.

In the present case of temporary part-time jobs taken by previously unemployed workers in Denmark, the assumption seems reasonable: Such temporary part-time jobs are not opened long term in advance, and are typically filled either by informal channels, by posting a vacancy in newspapers or on an internet media, or by making a phone call to the UI fund or the public employment service, who then mediates contact to an unemployed worker that might be interested. Normally, these job would then begin within a week or two. The Danish labour market is generally very flexible, as discussed in the introduction, implying that many vacancies are open for a very short time only, further strengthening the noanticipation assumption. In fact, in a database collecting all vacancies (part- and full-time) posted in Denmark in newspapers, internet media, via the public employment services, etc., the average vacancy duration is around 11 days (see Dimova et al., 2012). Presumably, finding a part-time job entails information problems to the same extent as finding a fulltime job, implying that even though the decision to search for part-time employment is 
endogenous, the availability of a suitable part-time job, and especially its timing with respect to an individual's time spent in unemployment, can be considered exogenous, introducing some random variation in the timing of the beginning of the treatment. Such random variation is sufficient to identify the parameters of interest in the econometric model.

The proportional hazard assumption is necessary for identifying the unobserved heterogeneity component. However, the presence of multiple spells per individual as well as time-varying year-quarter dummies in the model (included in order to capture changes in the labour market conditions) aids identification, too. As pointed out by Brinch (2007) and Gaure et al. (2007) among others, time-varying covariates provide a kind of exclusion restriction (as the past values of such variables affect the current hazard only through the selection process), which improves the identification of mixed hazard models in the sense that the identification does not hinge so much on the proportionality assumption. The multiple spells for the same individuals enhance the identification in a similar way.

Let $C_{i}$ be a non-censoring indicator that takes the value of 1 if spell $i$ was completed by the end of the observation period. The likelihood contribution of an individual with $N$ unemployment spells is specified as

$$
L=\iint\left(\prod_{i=1}^{N} L_{i}\left(v_{u}, v_{p}\right)\right) d G\left(v_{u}, v_{p}\right),
$$

where $G$ is the joint distribution function of the unobserved characteristics, and

$$
\begin{aligned}
L_{i}\left(v_{u}, v_{p}\right)= & \theta_{p}\left[t_{p i} \mid x_{i}, \tau_{i}, v_{p}\right]^{I\left[t_{p i}<t_{u i}\right]} \theta_{u}\left[t_{u i} \mid x_{i}, \tau_{i}, d_{1 i}\left(t_{u i}\right), d_{2 i}\left(t_{u i}\right), v_{u}\right]^{C_{i}} \\
& \times \exp \left\{-\int_{0}^{t_{p i}} \theta_{p}\left[s \mid x_{i}, \tau_{i}, v_{p}\right] d s-\int_{0}^{t_{u i}} \theta_{u}\left[s \mid x_{i}, \tau_{i}, d_{1 i}(s), d_{2 i}(s), v_{u}\right] d s\right\} .
\end{aligned}
$$

The unobserved characteristics, $v_{u}$ and $v_{p}$, are assumed to remain constant over different unemployment spells of the same individual, but our results are not sensitive with respect to this assumption as shown in Section 6.6.

The distribution $G$ is specified as bivariate discrete. Since the number of support points in this distribution is not known a priori, we estimate the model with varying numbers of support points. Namely, we begin with a model with $2 \times 2$ mass points and then expand the model by adding one support point at a time until the value of the likelihood function stabilizes. By specifying the discrete heterogeneity distribution in this way, we approximate the unknown true distribution function in a non-parametric fashion. Through this procedure we find 4 and 3 points of support for $v_{u}$ and $v_{p}$, respectively, for two models discussed below (one with homogeneous treatment effects and another with heterogeneous effects). The estimated distribution of unobserved heterogeneity is highly similar in these models, and in both cases the correlation between the unobserved heterogeneity terms is about -0.18 . 


\section{Results}

In this section, we first describe the raw transition data in order to observe patterns in the data. Next, we discuss in some detail the selection process and main parameters of interest from a model with homogeneous treatment effects across individuals. We then proceed to results from a model with heterogeneous treatment effects, and we illustrate and analyze these results in different ways.

\subsection{Empirical Hazards}

In Figure 1, we plot the Kaplan-Meier hazard rates out of unemployment as a function of elapsed unemployment duration. Specifically, four empirical hazard functions are depicted:

- (a) the hazard rate to supplementary UI benefits (from the 2nd week onwards),

- (b) the hazard out of unemployment for those not (yet) received supplementary UI benefits (from the 1st week onwards),

- (c) the hazard out of unemployment for those currently receiving supplementary UI benefits (from the 3 rd week onwards) ${ }^{6}$ and

- (d) the hazard out of unemployment for those who received supplementary UI benefits earlier in the current unemployment spell (from the 3rd week onwards).

Note that all the durations on the first axis are measured from the time of unemployment entry.

- Figure 1 about here -

The hazard rate into supplementary UI benefits is fairly large during the very early phases of unemployment (about $5 \%$ in the 2nd week), but it decreases over the first 20 unemployment weeks to around $0.5 \%$. Similarly, the hazard rate out of unemployment for those who have not (yet) received supplementary UI benefits is very large early in the unemployment spell but drops to a level around $2 \%$ after 30-40 weeks of unemployment. It is also evident from the figure that current recipients of supplementary UI benefits have the lowest hazard rates out of unemployment among the three groups (recipients, nonrecipients, past recipients) during the first year of unemployment, while those who have had a period of supplementary UI benefit receipt have the highest transition rate out of unemployment from the 6 th week of unemployment onwards.

These descriptive findings thus suggest the presence of an in-treatment effect reducing the transition rate out of unemployment while individuals are in treatment and a positive

\footnotetext{
${ }^{6}$ Note that this hazard rate is not well defined in the 2 nd week. When the worker who received supplementary UI benefits in the 2nd week leaves unemployment after that week, there will be only a single week of supplementary UI benefits at the end of the unemployment spell. But such a single week of supplementary benefits is ignored by construction, and thereby the hazard rate out of unemployment in the 2 nd week must be zero.
} 
post-treatment effect. However, these differences in the raw empirical hazard rates cannot be interpreted as causal effects, since they may be driven by differences in observed and unobserved characteristics. The selection into supplementary UI benefits is discussed in the next section.

\subsection{Selection into Supplementary UI Benefits}

The results from the estimation of the selection into supplementary UI benefits, that is, $\theta_{p}\left(t \mid x, \tau, v_{p}\right)$, are presented in the 2 nd and 3rd columns (coefficients and standard errors, respectively) of Table $2 .^{7}$

- Table 2 about here -

Duration dependence is negative, as indicated in the raw empirical hazard of Figure 1. In accordance with our descriptive findings, women - married as well as single - have a much higher transition rate to part-time employment with supplementary UI benefits than men. Moreover, married men have a higher transition rate into the treatment state than single men. Individuals aged 24 or below have a relatively high transition rate into supplementary benefits, while individuals aged 30-39 and 50-59 have the lowest transition rate. Given their weaker labour market attachment, part-time work may provide an effective way to accumulate work experience and obtain useful skills for young workers.

Compared to workers who are members of the metal workers' UI fund and those who are looking for work in the construction industry, the members of other UI funds typically enter part-time work with supplementary benefits at higher rates. Particularly sizeable and positive effects are found for white-collar workers, academics, and 'others'. NonWestern immigrants, the second generation in particular, are characterized by low hazards to supplementary UI benefits, something which was not evident from the raw data, while the Western immigrants do not differ noticeably from the native Danes in this respect. Past public transfers have a dynamic effect which is hard to interpret, but adding the 3 coefficients, it is not evident that past public income transfer dependence in general has a large impact. However, the number of weeks spent in unemployment during the year before the current unemployment spell has a distinct negative effect on the probability of becoming a supplementary UI benefit recipient. That effect is driven by experiences of full-time unemployment, as the time spent on supplementary UI benefits before the current spell has a strong positive effect.

\subsection{Homogenous Effects Model}

The 4th and 5th columns of Table 2 show the coefficients for the hazard rate out of unemployment. This hazard rate is uniformly decreasing until 52 weeks of unemployment, whereafter it appears fairly constant. Married men have the highest hazard rate out of unemployment, while single women have the lowest. Interestingly, married women have a

\footnotetext{
${ }^{7}$ The results for the model with heterogeneous treatment effects are almost identical (not reported here).
} 
higher transition rate out of unemployment than single men. The hazard rate is almost uniformly decreasing in age as found in several other studies. Unemployed workers who are members of the metal workers' UI fund or the construction workers' UI fund have higher transition rates out of unemployment than others, while those in the UI fund for (previously) self-employed individuals have the lowest hazard rates. As known from other studies, immigrants have lower exit rates than native Danes, especially those of NonWestern origin. The same holds for Non-Western 2nd generation immigrants. Having recently spent time on public income transfers is associated with a lower hazard rate, while more unemployment weeks in the past surprisingly has a positive influence. Note, however, that the weeks of past unemployment are also included in the weeks spent on public income transfers, so the implication is that individuals who spent time in unemployment, and on supplementary UI benefits in particular, leave unemployment at a higher rate than those who were on other public income transfer schemes for the same amount of time.

The two rows at the bottom of the table show the treatment effects, that is, the intreatment effect and the post-treatment effect. It is seen that, on average, current receipt of supplementary UI benefits causes a reduction in the transition rate out of unemployment of $55 \%(=(1-\exp (-0.792)) \times 100)$, as was also predicted by the theoretical model of Ek and Holmlund (2011). However, it also shows that the potentially positive in-treatment effects that were not included in the Ek and Holmlund model (search effectiveness/networks, human capital accumulation, signalling) are not sufficiently large to outweigh the negative effect, leaving the overall in-treatment effect clearly negative. On the other hand, having received supplementary UI benefits earlier in the unemployment spell causes an increase in the hazard rate of $32 \%$, which may be interpreted within the same framework as a network effect (new contacts obtained), a human capital effect (new skills learned), or a signalling effect (signalling willingness-to-work and sufficiently high productivity). This result immediately suggests that the net effect on unemployment duration will depend crucially on the length of the treatment period, and suggests moreover that attempts at reducing the treatment length may be beneficial, unless of course, the post-treatment effect depends on the length of the treatment period. In the next section, this issue is dealt with along with heterogeneous impacts in other dimensions.

\subsection{Heterogeneous Effects Model}

As outlined in the discussion of Ek and Holmlund (2011), a theoretical framework may provide some insights into what type of heterogeneous impacts we might expect to find. First of all, we may find different in-treatment effects due to different preferences for leisure relative to consumption; for example, we might expect larger lock-in effects for women and perhaps also for older workers. Second, different in-treatment effects may be due to differences in search effectiveness while in part-time employment, and here, we might expect immigrants and youth with less knowledge of local labour markets and search strategies to gain more. Finally, signalling may be more important to workers with 
less labour market experience, that is, to young workers, Non-Western immigrants, and workers having spent large fractions of time on public income transfer schemes. As regards post-treatment effects, we may expect once again network effects to be more important for workers with less access to employed networks, mainly immigrants. Human capital effects are likely to be important for workers with few formal skills and low labour market experience, and signalling effects may be important for the same groups as discussed for in-treatment effects.

The model with heterogeneous effects is otherwise similar to the model discussed above, but now the two treatment indicators $d_{1}(t)$ and $d_{2}(t)$ are interacted with the explanatory variables, $x{ }^{8}$ Hence, within sub-groups, the estimated effects are homogenous. The results are presented in Table 3. The table only shows parameters related to the effect of the treatment, while the other parameter estimates are available on request from the authors. The 2nd and 3rd columns show interaction effects of selected observed characteristics with the in-treatment indicator, while the 4 th and 5 th columns show interaction effects with the post-treatment indicator. Thus, the table provides a deeper analysis of how in-treatment and post-treatment effects vary among workers with different characteristics.

- Table 3 about here -

First of all, note that the in-treatment effect is present for the reference person, which is a newly unemployed single man aged 30-39 and member of the metal workers' UI fund. It is somewhat smaller in absolute value than the common in-treatment effect in the homogeneous effects model. Moreover, note that the absolute value of the in-treatment effect is decreasing in the elapsed unemployment duration at the time when an individual starts receiving supplementary UI benefits (and working part-time). One obvious reason for this is that the job finding rate is typically highest early in the unemployment spell, hence early takeup of part-time employment with supplementary UI benefits crowds out the most effective job search. Thus, one year after entry into unemployment, the decline in the hazard rate due to the in-treatment effect is reduced to $28 \%(=(1-\exp (-0.548+0.431 \times 0.52)) \times 100)$ from $42 \%$ at the time of inflow into unemployment. We also tested for quadratic effects, but there were none.

Women (single or married) have an in-treatment effect of about $-52 \%$ compared to the $-42 \%$ of the reference single male, while married men have the in-treatment effect of $-48 \%$. This is consistent with the 'higher preferences for leisure' hypothesis suggested above.

The in-treatment effect is less severe for workers below 25 and above 59, which might be due to search effectiveness effects and preferences for leisure. The in-treatment effect is particularly negative for individuals who are members of the UI funds of the construction industry, white collar workers and academics, which is difficult to explain with reference to theoretical arguments. We did not find any significant differential effect for immigrants.

\footnotetext{
${ }^{8}$ The treatment indicators were interacted with all explanatory variables, but those interactions not reported here were not statistically significant at the conventional risk levels and were therefore removed from the final model.
} 
Turning to the post-treatment effect, this increases the hazard rate out of unemployment for the reference person by $36 \%$. Having received treatment for one year during an unemployment spell increases the post-treatment effect to $66 \%$, i.e. almost a doubling. In 2008 (i.e. after our observation period) the rules were changed so that the maximum period on supplementary UI benefits is 26 weeks (reduced from 52), which will lead to a maximum post-treatment effect of $50 \%$. Again, there was absolutely no evidence of a non-linear effect. It is worth emphasising that possible endogeneity in the length of supplementary UI benefit spells is not accounted for. This suggests that our findings for the dependence of the post-treatment effect on the accumulated weeks of supplementary UI benefit should be treated with some caution.

The post-treatment effect is smallest for married women and largest for single men. These differences are hard to justify with reference to the theoretical model, except to the extent that they reflect the preferences for leisure argument, that unemployment in general has become more attractive for workers with higher preferences for leisure. The posttreatment effect is largest for the youngest age group, which is consistent with theoretical predictions and may be explained by signalling, network, and human capital effects. There is also a differential effect for members of the UI fund for the (previously) self-employed, which is hard to interpret, while we did not find differential effects for immigrants.

To sum up, spending time in supplementary UI benefits and working part-time (being treated) seems to be least beneficial for women and most beneficial for the young (and to some extent the old) age group, which is largely in accordance with our theoretical expectations. Moreover, we find that the in-treatment effect is negative and smaller in absolute terms the later during an unemployment spell a person participates in the treatment, and the positive post-treatment effect increases with the treatment duration. The latter implies an inherent conflict in the treatment; the longer the treatment lasts, the larger the accumulated negative in-treatment effect becomes, but on the other hand the positive posttreatment effect also increases with the treatment duration. This paradox can be further investigated by looking at net effects on the expected remaining unemployment duration, to which we turn in the next section.

\subsection{Expected Remaining Unemployment Duration}

A consequence of a negative in-treatment effect and a positive post-treatment effect is that the overall effect of part-time work with supplementary benefits on the expected remaining unemployment duration is ambiguous. It depends on the timing and duration of the treatment, and on the individual's characteristics. For these reasons, it is illustrative to compare expected remaining unemployment duration in counterfactual situations with and without periods of supplementary benefits. More specifically, we consider the following treatment effect:

$$
\Psi\left(x, t_{p}, t_{d}\right)=E\left(T_{u}-t_{p} \mid x, T_{p}=t_{p}, t_{d}, T_{u}>t_{p}\right)-E\left(T_{u}-t_{p} \mid x, T_{p}=\infty, T_{u}>t_{p}\right),
$$


where $t_{p}$ denotes the realised timing of the treatment, i.e. entry into supplementary UI benefits, and $t_{d}$ is the intended duration of the supplementary UI benefit period. In other words, $\Psi\left(x, t_{p}, t_{d}\right)$ measures the effect on the expected remaining unemployment duration of entering part-time work with supplementary UI benefit receipt at unemployment duration $t_{p}$ and staying there for (at most) $t_{d}$ weeks, compared to the counterfactual of no treatment, for a worker with observed characteristics $x .^{9}$

We consider nine different treatments by varying $t_{p} \in\{7.5,15,30\}$ and $t_{d} \in\{4,12,24\}$. These values describe the variation around the sample means of $t_{p}=15$ and $t_{d}=12$. Using the model with heterogeneous in-treatment and post-treatment effects, we compute the net effect of each of these nine treatment combinations for the subsample of workers in our sample who actually received supplementary benefits during a given unemployment spell. That is, for each worker we compute $\Psi\left(x, t_{p}, t_{d}\right)$ in each of the nine treatment combinations. This produces a sample distribution of $\Psi\left(x, t_{p}, t_{d}\right)$, whose variation for a given treatment combination come from 1) variation in the treatment effects across sub-groups, and 2) variation in observed characteristics (since the treatment effect is multiplicative). Hence, some of the variation is a result of the model specification and we should thus be cautious when interpreting distributional aspects of the treatment effects.

The results from this exercise are reported in Table $4 .{ }^{10}$ The first two columns of Table 4 characterize the treatment in question. Columns 3 and 4 report the sample averages of the expected remaining unemployment durations with and without the treatment, respectively. Their difference in column 5 is the average treatment effect on the treated. The remaining columns in Table 4 characterize the sample distribution of treatment effects across treated workers.

- Table 4 about here -

As seen in Table 4, the in-treatment effect tends to dominate the post-treatment effect at longer treatment durations, while the treatment effects generally increase (in absolute value) with the elapsed unemployment duration at the time of treatment. It is also obvious that the optimal treatment duration is fairly low and that treatment durations of 24 weeks or more tend to lead to increasing remaining unemployment duration on average.

Turning to the distributions of the treatment effects, there are groups of individuals who gain from all the 9 treatments shown here, and in nearly all cases there are at least $25 \%$ of the treated who experience longer unemployment duration as a result of the treatment. The question of obvious interest now is who tend to benefit from supplementary UI benefit periods and who do not? To address this question, we report mean characteristics of workers in the 1st and 10th deciles of the treatment effect distribution in Table 5, where the treatment corresponds to the supplementary UI benefit period that starts after 15

\footnotetext{
${ }^{9}$ The calender-time effects are held constant over time.

${ }^{10}$ Note that it is not possible to do the same for the actual treatments given to individuals in the sample, since we do not know the intended duration of treatments for individuals exiting unemployment while in treatment. In order to calculate the expected remaining duration, the entire treatment process during the unemployment spell must be known.
} 
weeks of full-time unemployment and lasts at most 12 weeks. The workers in the 1 st decile have the largest reduction in the expected remaining unemployment duration resulting from the treatment, and those in the 10th decile have the largest increase in the expected remaining unemployment duration.

- Table 5 about here -

As one may already have suspected from the estimation results, the 10th decile is dominated by married women. Moreover, $55 \%$ of them are members of the white collar workers' UI fund, and $28 \%$ are members of the manufacturing industry workers' UI fund. They are almost all 30-59 years old.

Those who gain most from taking a part-time job with supplementary UI benefits are less clearly identified; both men and women belong to this group. Still, more than $70 \%$ of those with the highest reduction in the remaining unemployment duration are below 30 , and they are often members of the UI funds in the categories 'Others', '(previously) selfemployed', and 'trade'. Finally, this group includes a fairly large fraction of Non-Western immigrants, suggesting the use of part-time work with supplementary benefits as a way into the labour market for immigrants. Thus, even if we did not find significant heterogeneous impacts for Non-Western immigrants, they do seem to experience overall gains from the treatment, which would be in accordance with our theoretically founded expectations.

\subsection{Robustness Checks}

In the data, some workers move between full-time unemployment and part-time work with supplementary UI benefits almost on a regular basis. It seems likely that these workers return repeatedly to the same part-time job, which of course has very different implications than a sequence of different part-time jobs. This raises the question how such observations should be treated in the data. In the absence of a definite answer, we check the robustness of our results with respect to different definitions of the treatment and of an unemployment spell. Namely, we simply ignore all periods of supplementary benefits shorter than 3 or 5 weeks (which are thus regarded as regular full-time unemployment). These results for the in-treatment and post-treatment effects obtained from the homogenous effect model are shown in the rows $\mathrm{B}$ and $\mathrm{C}$ of Table 6 . Compared to our baseline treatment effects in row $\mathrm{A}$, both the in-treatment and post-treatment effects fall in absolute value but remain statistically significant. Thus a less negative in-treatment effect is compensated by a smaller positive post-treatment effect, suggesting that the overall effect on the expected duration is relatively robust.

- Table 6 about here -

Recall that the unemployment spells which begin with a supplementary UI benefit period lasting more than one week have been excluded from our sample. As a robustness check, we add these spells to the analysis by generating an artificial 0.1 -week period of 
full-time unemployment to the beginning of such unemployment periods. It turns out that including these spells in the analysis only has a modest effect on the estimates (row D).

We have specified unobserved heterogeneity at the individual level, so that multiple spells of unemployment for the same individuals have been exploited for identification of the joint distribution of the heterogeneity terms. While this is very convenient for computational purposes, the assumption that the values of unobserved characteristics do not vary over spells can be rather strong. Thus we re-estimate the model without exploiting multiple spells for identification by assuming spell-specific unobserved heterogeneity terms. The resulting in- and post-treatment effects in row $\mathrm{E}$ are in line with our baseline model, although only $2 \times 2$ mass points in the heterogeneity distribution are detected in this case.

Next we turn to the results obtained without covariates for the time spent in unemployment and on supplementary UI benefits during the year preceding the beginning of the unemployment spell. These covariates may be problematic as they are potentially correlated with the unobserved characteristics. To some extent, our model deals with the endogeneity of the time spent in unemployment in the past year as that variable can be viewed as the modelled outcome in the repeated spells. But this argument does not apply to individual's first unemployment spell. Nor is it strictly valid for the time spent on supplementary UI benefits, as we only model transitions into supplementary UI benefits, not the length of such benefit periods. In any case, dropping these two covariates from the model does not alter our results, as shown in row $\mathrm{F}$.

- Table 7 about here -

As a final robustness check, we estimate the model with homogeneous treatment effects separately for 19 worker groups defined by the background variables with which the treatment dummies were interacted in our heterogeneous treatment effects model. This provides an alternative way to assess impact heterogeneity across different groups of workers. These results are shown in columns 2 to 5 of Table 7 . The next two columns report the corresponding average treatment effects based on the parameter estimates in Table 3. The average in-treatment effect for a given group is computed using the average values of the interacting covariates measured at the beginning of supplementary UI benefit spells for the group in the question. Analogously, the average post-treatment effect is evaluated at the average values of the covariates at the beginning of full-time unemployment following receipt of supplementary UI benefits. The approach based on sub-samples is more flexible in the sense that the entire model, including the shape of baseline hazards, the effects of all covariates, and the distribution of the unobserved characteristics, can vary freely across the groups. On the other hand, the model with heterogeneous treatment effects in Table 3 allows additional impact heterogeneity within groups defined by marital status, age group or UI fund only; the treatment effects among married women, for example, vary with age and UI fund, something that is ruled out when estimating the model from the sub-sample of married women. Keeping these differences in mind, it is interesting to compare the group-specific effects between the two approaches. 
By and large, the estimated effects are fairly similar with a few exceptions. For men (married and single) the model with heterogeneous treatment effects produces somewhat higher post-treatment effects but very similar in-treatment effects. Large differences are only found for individuals younger than 25 and for the members of the UI fund for (previously) self-employed. For these two groups the average lock-in effect is clearly less negative while the average post-treatment effect is much higher than the corresponding sub-sample estimates in columns 2 and 4 . This suggests the possibility that the overall effect of parttime work with supplementary UI benefits may be overstated to some extent for these groups. There are similar but much smaller differences in the estimates between the two approaches for individuals aged 25-29, for the oldest group and for the members of certain UI funds. It is worth noting that, despite the difference in the estimates for the individuals younger than 25, the sub-sample estimates for age groups are reasonably similar, as they also indicate that the youngest group has the smallest in-treatment effect (in absolute value) and the largest post-treatment effect. When it comes to the differences by the UI fund, one should note that many of the average effects in Table 7 rely on statistically insignificant coefficients (including a positive in-treatment interaction effect of the UI fund for self-employed).

\section{Conclusions}

The present study provides evidence on the effect of part-time work with supplementary UI benefits on unemployment duration. The sign and magnitude of the treatment effect vary with individual characteristics and with the timing and length of the supplementary UI benefit period. On average, in our sample of Danish workers, receiving supplementary UI benefits and working part-time reduces remaining unemployment duration. However, due to the presence of a negative in-treatment effect, longer spells of supplementary benefits tend to prolong unemployment duration, even though the positive post-treatment effect also increases with the treatment duration. Moreover, it tends to increase unemployment duration for married women, white collar workers and manufacturing workers.

However, the effects are much better for certain other groups of workers, particularly those with short supplementary benefit periods. Young workers and 1st generation NonWestern immigrants typically benefit from the receipt of supplementary UI benefits in terms of reduced expected unemployment duration. This implies that, at least for some types of workers, part-time work with supplementary UI benefits may work as a stepping stone to regular employment. Specifically, it makes sense that young workers and immigrants can benefit from short part-time jobs since they need (a) to develop their work experience and skills, (b) to enlarge their network among employed workers, and (c) to signal their motivation and knowledge in order to increase the number of job offers and ultimately improve upon their labour market career prospects.

A general lesson from our analysis is that the current uniform scheme of supplementary UI benefits on average works well, but it may still be improved. Specifically, the large 
degree of impact heterogeneity implies some potential policy improvements. More intensive monitoring of job search efforts could be used to mitigate the adverse effects found for some groups. The supplementary UI benefit scheme could - to some extent - be targeted at the groups that are most likely to benefit from it. If all groups of unemployed workers have to be covered, the maximum duration and compensation level could be varied across the groups.

From a cost-benefit perspective, the fact that the policy overall reduces unemployment duration almost surely implies that a cost-benefit analysis would favour it; workers who would otherwise be full-time unemployed are 1) contributing to the aggregate production, and 2) requiring fewer UI benefits than full-time unemployed workers. Naturally, there may be various substitution and general equilibrium effects, but in the sense that this policy increases effective labour supply, and that it may fill a gap in ensuring labour supply for (part-time) jobs that would not be filled otherwise, it is hard to see how a cost-benefit analysis would become unfavourable. Still, the outcome of a cost-benefit analysis might be even more beneficial, if some of the improvements discussed above were implemented. 


\section{Acknowledgments}

Tomi Kyyrä acknowledges financial support from the Academy of Finland. Pierpaolo Parrotta acknowledges the financial support from the Graduate School for Integration, Production and Welfare, and the Swiss National Centres of Competence in Research LIVES. Michael Rosholm acknowledges financial support from the Social Science Research Foundation, grant no. 275-05-0273.

\section{References}

[1] Abbring, J.H., Van den Berg, G.J., 2003. The non-parametric identification of treatment effects in duration models. Econometrica, 71, 1491-1517.

[2] Booth, A.L., Dolado, J.J., Frank, J., 2002. Symposium on temporary work: Introduction. The Economic Journal, 112, F181-F188.

[3] Cockx, B., Picchio, M., 2012. Are short-lived jobs stepping stones to longlasting jobs? Oxford Bulletin of Economics and Statistics, forthcoming.

[4] Brinch, C. N., 2007. Nonparametric identification of the mixed hazards model with time-varying covariates. Econometric Theory, 23, 349-354.

[5] De Graaf-Zijl, M., Van den Berg, G.J., Heyma, A., 2011. Stepping-stones for the unemployed: the effect of temporary jobs on the duration until (regular) work. Journal of Population Economics 24(1), 107-139.

[6] Dimova, S., Nyland, S., Rosholm, M., 2012. Unemployment duration, case workers, vacancies, and cyclical variations. Unpublished manuscript.

[7] Ek, S., Holmlund, B., 2011. Part-Time unemployment and optimal unemployment insurance. IZA Discussion Papers 5540. IZA, Bonn.

[8] Gaure, S., Røed, K., Zhang, T., 2007. Time and causality: A Monte Carlo assessment of the timing-of-events approach. Journal of Econometrics, 141, 1159-1195.

[9] Holen, A., Horowitz, S., 1974. Partial unemployment insurance benefits and the extent of partial unemployment. The Journal of Human Resources, 9, 420-422.

[10] Houseman, S.N., Kalleberg, A.L., Erickcek, G.A., 2003. The role of temporary help employment in tight labour markets. Industrial and Labor Relations Review, 57(1), 105-127.

[11] Heinrich, C.J., Mueser, P.R., Troske, K.R., 2005. Welfare to temporary work: Implications for labour market outcomes. The Review of Economics and Statistics, 87, 154-173. 
[12] Jahn, E.J., Rosholm, M., 2010. Looking beyond the bridge: How temporary agency employment affects labor market outcomes. IZA Discussion Paper 4973. IZA, Bonn.

[13] Kyyrä, T., 2010. Partial unemployment insurance benefits and the transition rate to regular work. European Economic Review, 54 (7), 911-930.

[14] Hartman, L., Lindqvist, L., Skans Nordström, O.N., 2010. Stepping-stones, dead-ends, or both? An analysis of Swedish replacement contracts. Empirical Economics, 38, 645-668.

[15] McCall, B., 1996. Unemployment insurance rules, joblessness, and part-time work. Econometrica, 64, 647-682.

[16] McCall, B., 1997. The determinants of full-time versus part-time reemployment following job displacement. Journal of labour Economics, 15 (4), 714734 .

[17] Møller, I.H., Lind, J., 2000. The labour market in process of change?: Some critical comments. International Journal of Employment Studies, 8(1), 155195 .

[18] Munts, R., 1970. Partial benefit schedules in unemployment insurance: Their effects on work incentives. The Journal of Human Resources, 5, 160-176.

[19] Rasmussen, E., Lind, J., Visser, J., 2004. Divergence in part-time work in New Zealand, the Netherlands and Denmark. British Journal of Industrial Relations, 42(4), 637-658.

[20] Rosholm, M., 2008. Experimental evidence on the nature of the Danish employment miracle. IZA Discussion Paper 3620. IZA, Bonn.

[21] Røed, K., Westlie, L., 2012. Unemployment insurance in welfare states: Soft constraints and mild sanctions. Journal of the European Economic Association, 10(3), 518-554..

[22] Staghøj, J., Svarer, M., Rosholm, M., 2010. Choosing the best training programme: Is there a case for statistical treatment rules? Oxford Bulletin of Economics and Statistics, 72(2), 172-201.

[23] Svarer, M., 2011. The effect of sanctions on the exit rate from unemployment: Evidence from Denmark. Economica, 78, 751-778. 
Figure 1: Empirical hazard rates into supplementary UI benefits and employment

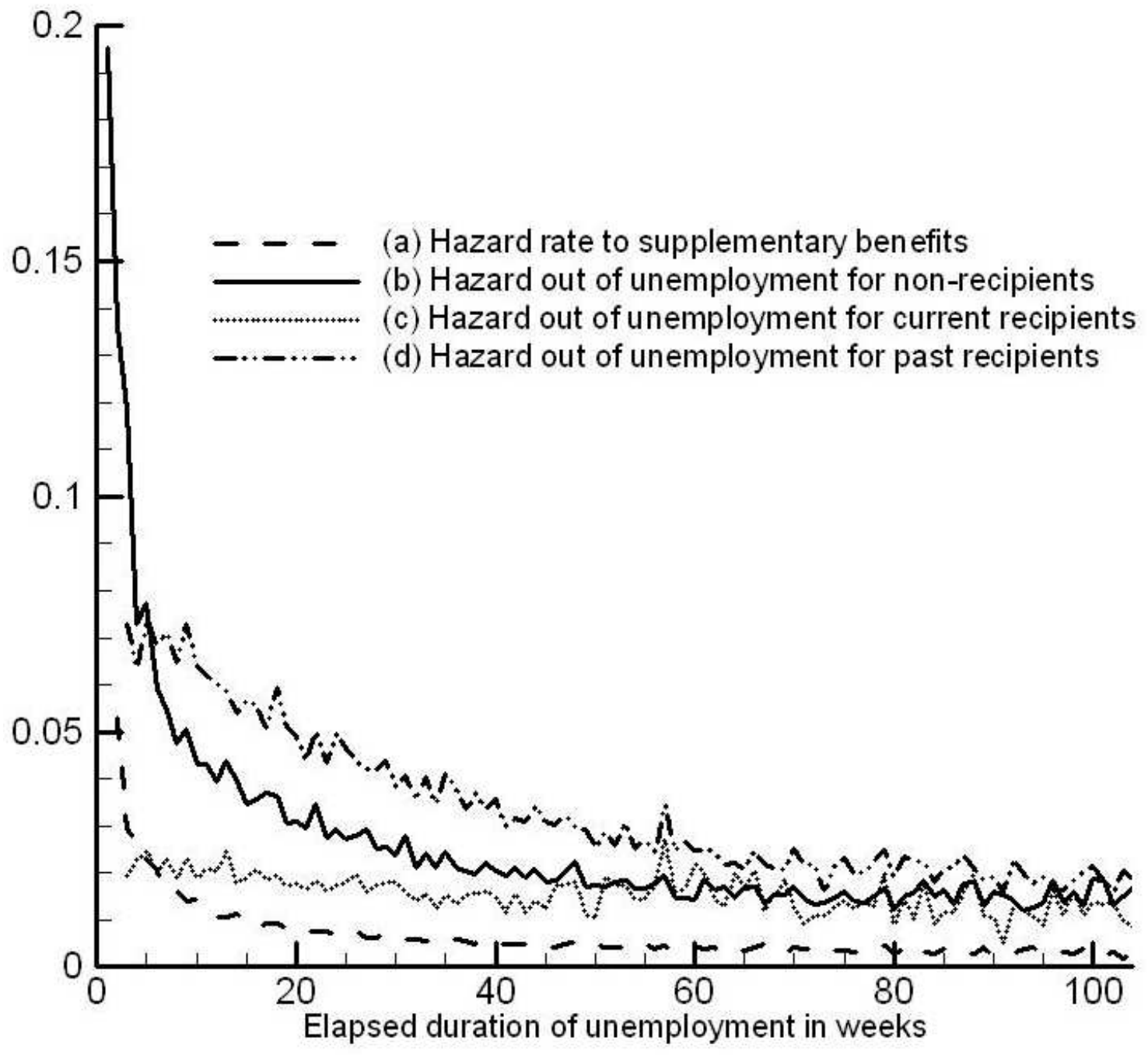


Table 1: Sample statistics for non-recipients and recipients of supplementary UI benefits

\begin{tabular}{|c|c|c|c|c|}
\hline & \multicolumn{2}{|c|}{ Non-recipients } & \multicolumn{2}{|c|}{ Recipients } \\
\hline & Mean & Std.Dev. & Mean & Std.Dev. \\
\hline \multicolumn{5}{|l|}{ Family status: } \\
\hline Married woman & 0.300 & 0.458 & 0.371 & 0.483 \\
\hline Married man & 0.268 & 0.443 & 0.186 & 0.389 \\
\hline Single woman & 0.175 & 0.380 & 0.261 & 0.439 \\
\hline Single man & 0.257 & 0.437 & 0.182 & 0.386 \\
\hline \multicolumn{5}{|l|}{ Age: } \\
\hline less than 25 & 0.079 & 0.270 & 0.087 & 0.282 \\
\hline $25-29$ & 0.175 & 0.380 & 0.169 & 0.374 \\
\hline $30-39$ & 0.325 & 0.469 & 0.303 & 0.459 \\
\hline $40-49$ & 0.217 & 0.412 & 0.223 & 0.417 \\
\hline $50-59$ & 0.184 & 0.387 & 0.196 & 0.397 \\
\hline above 59 & 0.020 & 0.141 & 0.023 & 0.149 \\
\hline \multicolumn{5}{|l|}{ UI fund: } \\
\hline Construction industry & 0.030 & 0.170 & 0.012 & 0.110 \\
\hline Manufacturing industry & 0.363 & 0.481 & 0.271 & 0.445 \\
\hline Technicians & 0.048 & 0.214 & 0.043 & 0.203 \\
\hline White collar workers & 0.114 & 0.318 & 0.173 & 0.378 \\
\hline Academics & 0.081 & 0.273 & 0.093 & 0.291 \\
\hline Others & 0.167 & 0.323 & 0.219 & 0.399 \\
\hline Self-employed & 0.024 & 0.152 & 0.026 & 0.159 \\
\hline Metal Industry & 0.061 & 0.239 & 0.029 & 0.166 \\
\hline Trade & 0.113 & 0.316 & 0.134 & 0.341 \\
\hline \multicolumn{5}{|l|}{ Nationality: } \\
\hline Danish & 0.907 & 0.290 & 0.904 & 0.295 \\
\hline Western immigrant & 0.024 & 0.154 & 0.027 & 0.163 \\
\hline Non-Western Immigrant & 0.060 & 0.237 & 0.060 & 0.237 \\
\hline 2nd gen. Western immigrant & 0.004 & 0.065 & 0.005 & 0.068 \\
\hline 2nd gen. Non-Western immigrant & 0.005 & 0.069 & 0.004 & 0.066 \\
\hline \multicolumn{5}{|l|}{ Public income transfer: } \\
\hline $0-1$ year ago & 0.329 & 0.318 & 0.408 & 0.349 \\
\hline 1-2 years ago & 0.447 & 0.375 & 0.441 & 0.389 \\
\hline $2-3$ years ago & 0.408 & 0.391 & 0.436 & 0.402 \\
\hline \multicolumn{5}{|c|}{ Fraction of time in unemployment $0-1$ year ago: } \\
\hline on UI benefits & 0.242 & 0.263 & 0.275 & 0.290 \\
\hline on supplementary UI benefits & 0.018 & 0.070 & 0.055 & 0.124 \\
\hline Unemployment duration (in weeks) & 16.3 & 31.7 & 48.1 & 51.0 \\
\hline Number of spells & \multicolumn{2}{|c|}{190,678} & \multicolumn{2}{|c|}{43,392} \\
\hline
\end{tabular}


Table 2: Results from model with homogeneous treatment effects

\begin{tabular}{|c|c|c|c|c|}
\hline \multirow{3}{*}{ Baseline hazard (weeks): } & \multicolumn{2}{|c|}{$\begin{array}{c}\text { Hazard into } \\
\text { treatment }\end{array}$} & \multicolumn{2}{|c|}{$\begin{array}{l}\text { Hazard out of } \\
\text { unemployment }\end{array}$} \\
\hline & Coeff. & Std.Err. & \multirow[t]{2}{*}{ Coeff. } & \multirow[t]{2}{*}{ Std.Err } \\
\hline & & & & \\
\hline $0-4$ & -2.828 & 0.059 & -2.123 & 0.026 \\
\hline $4-8$ & -3.296 & 0.061 & -2.807 & 0.026 \\
\hline $8-12$ & -3.565 & 0.062 & -3.015 & 0.026 \\
\hline $12-16$ & -3.726 & 0.063 & -3.113 & 0.027 \\
\hline $16-20$ & -3.865 & 0.065 & -3.198 & 0.027 \\
\hline $20-25$ & -3.963 & 0.065 & -3.288 & 0.028 \\
\hline $25-35$ & -4.107 & 0.064 & -3.392 & 0.027 \\
\hline $35-52$ & -4.297 & 0.065 & -3.557 & 0.027 \\
\hline $52-79$ & -4.433 & 0.066 & -3.692 & 0.028 \\
\hline $79-104$ & -4.631 & 0.073 & -3.762 & 0.029 \\
\hline $104-156$ & -4.708 & 0.074 & -3.741 & 0.029 \\
\hline $156-$ & -4.740 & 0.090 & -3.482 & 0.033 \\
\hline \multicolumn{5}{|l|}{ Family status (vs. single man): } \\
\hline Married woman & 0.457 & 0.019 & 0.067 & 0.008 \\
\hline Married man & 0.115 & 0.020 & 0.238 & 0.009 \\
\hline Single woman & 0.528 & 0.020 & -0.074 & 0.009 \\
\hline \multicolumn{5}{|l|}{ Age (vs.30-39): } \\
\hline less than 25 & 0.276 & 0.024 & 0.077 & 0.012 \\
\hline $25-29$ & 0.082 & 0.018 & 0.084 & 0.008 \\
\hline $40-49$ & 0.104 & 0.017 & -0.102 & 0.007 \\
\hline $50-59$ & -0.020 & 0.018 & -0.301 & 0.008 \\
\hline above 59 & 0.079 & 0.039 & -0.312 & 0.019 \\
\hline \multicolumn{5}{|l|}{ UI fund (vs. Metal): } \\
\hline Construction industry & -0.097 & 0.055 & -0.012 & 0.022 \\
\hline Manufacturing industry & 0.329 & 0.028 & -0.122 & 0.010 \\
\hline Technicians & 0.330 & 0.038 & -0.381 & 0.015 \\
\hline White collar workers & 0.923 & 0.031 & -0.143 & 0.012 \\
\hline Academics & 0.573 & 0.034 & -0.341 & 0.014 \\
\hline Others & 0.781 & 0.030 & -0.410 & 0.012 \\
\hline Self-employed & 0.137 & 0.043 & -0.643 & 0.020 \\
\hline Trade & 0.402 & 0.032 & -0.366 & 0.013 \\
\hline \multicolumn{5}{|l|}{ Nationality (vs. Danish): } \\
\hline Western immigrant & -0.040 & 0.039 & -0.155 & 0.018 \\
\hline Non-Western Immigrant & -0.174 & 0.027 & -0.399 & 0.012 \\
\hline 2nd gen. Western immigrant & 0.027 & 0.100 & -0.012 & 0.045 \\
\hline 2nd gen. Non-Western immigrant & -0.289 & 0.098 & -0.323 & 0.049 \\
\hline \multicolumn{5}{|c|}{ Fraction of time on public income transfers: } \\
\hline $0-1$ year ago & 0.120 & 0.024 & -0.912 & 0.012 \\
\hline 1-2 years ago & -0.275 & 0.022 & 0.671 & 0.009 \\
\hline $2-3$ years ago & 0.097 & 0.019 & -0.047 & 0.008 \\
\hline \multicolumn{5}{|c|}{ Fraction of time spent unemployed 0-1 year ago: } \\
\hline on unemployment benefits & -0.352 & 0.027 & 0.229 & 0.013 \\
\hline on supplementary UI benefits & 2.927 & 0.045 & 0.445 & 0.029 \\
\hline \multicolumn{5}{|l|}{ Treatment Effects: } \\
\hline In-treatment & & & -0.792 & 0.013 \\
\hline Post-treatment & & & 0.276 & 0.008 \\
\hline
\end{tabular}

Notes: Numbers in bold are statistically significant at the $5 \%$ level. The model also includes indicators for county of residence, time-varying year-quarter indicators, and parameters for the distribution of unobserved characteristics. 
Table 3: Heterogeneous treatment effects

\begin{tabular}{|c|c|c|c|c|}
\hline & \multicolumn{2}{|c|}{ In-treatment } & \multicolumn{2}{|c|}{ Post-treatment } \\
\hline & Coeff. & Std.Err. & Coeff. & Std.Err. \\
\hline Effect for reference person (Intercept) & -0.548 & 0.065 & 0.306 & 0.031 \\
\hline Elapsed unemployment duration/100 & 0.431 & 0.024 & & \\
\hline Accumulated past weeks of supplementary UI benefits $/ 100$ & & & 0.389 & 0.037 \\
\hline \multicolumn{5}{|l|}{ Family status (vs. single man): } \\
\hline Married woman & -0.199 & 0.037 & -0.159 & 0.019 \\
\hline Married man & -0.097 & 0.042 & -0.049 & 0.021 \\
\hline Single woman & -0.172 & 0.039 & -0.100 & 0.020 \\
\hline \multicolumn{5}{|l|}{ Age (vs.30-39): } \\
\hline less than 25 & 0.313 & 0.049 & 0.353 & 0.026 \\
\hline $25-29$ & 0.086 & 0.037 & 0.152 & 0.019 \\
\hline $40-49$ & -0.009 & 0.032 & -0.015 & 0.017 \\
\hline $50-59$ & -0.045 & 0.034 & -0.059 & 0.019 \\
\hline above 59 & 0.213 & 0.078 & 0.041 & 0.051 \\
\hline \multicolumn{5}{|l|}{ UI fund (vs. Metal): } \\
\hline Construction industry & -0.389 & 0.159 & 0.055 & 0.061 \\
\hline Manufacturing industry & -0.148 & 0.061 & -0.044 & 0.030 \\
\hline Technicians & -0.306 & 0.082 & -0.033 & 0.043 \\
\hline White collar workers & -0.469 & 0.065 & -0.034 & 0.033 \\
\hline Academics & -0.391 & 0.072 & 0.014 & 0.035 \\
\hline Others & -0.281 & 0.064 & 0.013 & 0.032 \\
\hline Self-employed & 0.159 & 0.088 & 0.244 & 0.051 \\
\hline Trade & -0.160 & 0.067 & 0.056 & 0.034 \\
\hline
\end{tabular}

Notes: Numbers in bold are statistically significant at the $5 \%$ level. The reference person is a single male aged 30-39 and member of the metal industry workers' UI fund, has elapsed unemployment duration of 0 when starting treatment and 0 weeks of accumulated treatment in the past when finishing treatment.

Table 4: Expected remaining durations and treatment effects

\begin{tabular}{|c|c|c|c|c|c|c|c|c|c|c|c|}
\hline \multicolumn{2}{|c|}{ Treatment } & \multicolumn{2}{|c|}{$\begin{array}{c}\text { Average expected remaining } \\
\text { unemployment duration }\end{array}$} & \multirow{2}{*}{$\begin{array}{c}\text { Average } \\
\text { treatment } \\
\text { effect } \\
\Psi\left(x, t_{p}, t_{d}\right)\end{array}$} & \multicolumn{7}{|c|}{ Percentiles of treatment effects $\Psi\left(x, t_{p}, t_{d}\right)$} \\
\hline$t_{p}$ & $t_{d}$ & $T_{p}=t_{p}$ & $T_{p}=\infty$ & & $5 \%$ & $10 \%$ & $25 \%$ & $50 \%$ & $75 \%$ & $90 \%$ & $95 \%$ \\
\hline 7.5 & 4 & 25.2 & 31.9 & -6.7 & -21.0 & -16.0 & -9.4 & -4.8 & -1.8 & 0.2 & 1.0 \\
\hline 7.5 & 12 & 30.5 & 31.9 & -1.4 & -15.6 & -10.6 & -4.1 & 0.5 & 3.3 & 5.1 & 6.0 \\
\hline 7.5 & 24 & 36.5 & 31.9 & 4.6 & -9.4 & -4.4 & 2.0 & 6.3 & 9.3 & 11.4 & 12.5 \\
\hline 15 & 4 & 20.6 & 28.0 & -7.5 & -22.1 & -17.1 & -10.4 & -5.5 & -2.4 & -0.3 & 0.6 \\
\hline 15 & 12 & 25.4 & 28.0 & -2.7 & -17.4 & -12.2 & -5.5 & -0.7 & 2.4 & 4.3 & 5.1 \\
\hline 15 & 24 & 31.1 & 28.0 & 3.1 & -11.4 & -6.4 & 0.3 & 5.0 & 8.0 & 10.0 & 11.2 \\
\hline 30 & 4 & 9.4 & 17.7 & -8.3 & -23.4 & -18.3 & -11.4 & -6.4 & -3.1 & -0.9 & 0.1 \\
\hline 30 & 12 & 13.4 & 17.7 & -4.3 & -19.5 & -14.3 & -7.4 & -2.4 & 1.0 & 3.2 & 4.0 \\
\hline 30 & 24 & 18.7 & 17.7 & 1.0 & -14.2 & -9.0 & -2.1 & 2.9 & 6.2 & 8.3 & 9.6 \\
\hline
\end{tabular}


Table 5: Mean characteristics of the treated workers in the 1st and 10th deciles of the treatment effect distribution for treatment $t_{p}=15$ and $t_{d}=12$.

\begin{tabular}{|c|c|c|}
\hline & 1st decile & 10th decile \\
\hline \multicolumn{3}{|l|}{ Family status: } \\
\hline Married woman & 0.199 & 0.859 \\
\hline Married man & 0.112 & 0.029 \\
\hline Single woman & 0.361 & 0.111 \\
\hline Single man & 0.329 & 0.001 \\
\hline \multicolumn{3}{|l|}{ Age: } \\
\hline Less than 25 & 0.461 & 0.000 \\
\hline $25-29$ & 0.242 & 0.008 \\
\hline $30-39$ & 0.101 & 0.317 \\
\hline $40-49$ & 0.074 & 0.278 \\
\hline $50-59$ & 0.088 & 0.396 \\
\hline Above 59 & 0.034 & 0.001 \\
\hline \multicolumn{3}{|l|}{ UI fund: } \\
\hline Construction industry & 0.008 & 0.001 \\
\hline Manufacturing industry & 0.106 & 0.276 \\
\hline Technicians & 0.033 & 0.031 \\
\hline White collar workers & 0.028 & 0.550 \\
\hline Academics & 0.086 & 0.043 \\
\hline Others & 0.226 & 0.095 \\
\hline Self-employed & 0.181 & 0.000 \\
\hline Metal industry & 0.032 & 0.000 \\
\hline Trade & 0.301 & 0.004 \\
\hline \multicolumn{3}{|l|}{ Nationality: } \\
\hline Danish & 0.834 & 0.952 \\
\hline Western immigrant & 0.029 & 0.024 \\
\hline Non-Western immigrant & 0.114 & 0.019 \\
\hline 2nd gen. Western immigrant & 0.003 & 0.004 \\
\hline 2nd gen. Non-Western immigrant & 0.019 & 0.000 \\
\hline \multicolumn{3}{|c|}{ Fraction of time on public income transfers: } \\
\hline $0-1$ year ago & 0.494 & 0.360 \\
\hline $1-2$ years ago & 0.320 & 0.531 \\
\hline $2-3$ years ago & 0.356 & 0.481 \\
\hline \multicolumn{3}{|c|}{ Fraction of time spent unemployed 0-1 year ago: } \\
\hline on unemployment benefits & 0.215 & 0.298 \\
\hline on supplementary UI benefits & 0.026 & 0.080 \\
\hline
\end{tabular}


Table 6: Robustness analysis

\begin{tabular}{lllllll}
\hline & & \multicolumn{2}{c}{ In-treatment } & & \multicolumn{2}{c}{ Post-treatment } \\
Specification: & Coeff. & Std.Err. & & Coeff. & Std.Err. \\
\hline A. Baseline model & & & & & \\
B. SUIB subspells shorter than 3 weeks ignored & $\mathbf{- 0 . 4 6 8}$ & 0.013 & & $\mathbf{0 . 2 1 4}$ & 0.011 \\
C. SUIB subspells shorter than 5 weeks ignored & & $\mathbf{- 0 . 2 2 1}$ & 0.012 & & $\mathbf{0 . 1 4 4}$ & 0.012 \\
D. Workers immediately on SUIB included & & $\mathbf{0 . 7 8 6}$ & 0.011 & & $\mathbf{0 . 2 3 7}$ & 0.008 \\
E. Unobserved heterogeneity at spell level & & $\mathbf{0 . 8 4 6}$ & 0.014 & & $\mathbf{0 . 2 5 4}$ & 0.010 \\
F. Covariates for time spent on UI benefits excluded & $\mathbf{- 0 . 7 9 6}$ & 0.013 & & $\mathbf{0 . 2 6 3}$ & 0.008 \\
\hline
\end{tabular}

Notes: All results are based on the model specification with homogeneous treatment effects. Numbers in bold are statistically significant at the $5 \%$ level.

Table 7: Treatment effects by group

\begin{tabular}{|c|c|c|c|c|c|c|}
\hline & \multicolumn{4}{|c|}{ Homogeneous effects from sub-samples } & \multirow{2}{*}{\multicolumn{2}{|c|}{$\begin{array}{l}\text { Average effects from the model with } \\
\text { heterogeneous treatment effects }\end{array}$}} \\
\hline & \multicolumn{2}{|c|}{ In-treatment } & \multicolumn{2}{|c|}{ Post-treatment } & & \\
\hline & Coeff. & Std.Err. & Coeff. & Std.Err. & In-treatment & Post-treatment \\
\hline \multicolumn{7}{|l|}{ By family status: } \\
\hline Single men & -0.648 & 0.033 & 0.319 & 0.018 & -0.588 & 0.403 \\
\hline Single women & -0.793 & 0.026 & 0.319 & 0.017 & -0.768 & 0.319 \\
\hline Married men & -0.753 & 0.031 & 0.234 & 0.018 & -0.710 & 0.310 \\
\hline Married women & -0.814 & 0.020 & 0.264 & 0.014 & -0.814 & 0.226 \\
\hline \multicolumn{7}{|l|}{ By age group: } \\
\hline less than 25 & -0.645 & 0.048 & 0.339 & 0.032 & -0.470 & 0.621 \\
\hline $25-29$ & -0.847 & 0.034 & 0.291 & 0.022 & -0.745 & 0.404 \\
\hline $30-39$ & -0.829 & 0.023 & 0.248 & 0.015 & -0.801 & 0.253 \\
\hline $40-49$ & -0.766 & 0.028 & 0.304 & 0.018 & -0.781 & 0.245 \\
\hline $50-59$ & -0.792 & 0.030 & 0.210 & 0.020 & -0.773 & 0.215 \\
\hline above 59 & -0.647 & 0.102 & 0.193 & 0.080 & -0.562 & 0.337 \\
\hline \multicolumn{7}{|l|}{ By UI fund: } \\
\hline Metal industry & -0.523 & 0.086 & 0.360 & 0.041 & -0.437 & 0.353 \\
\hline Construction industry & -1.019 & 0.178 & 0.143 & 0.063 & -0.831 & 0.397 \\
\hline Manufacturing industry & -0.630 & 0.024 & 0.298 & 0.015 & -0.633 & 0.251 \\
\hline Technicians & -0.865 & 0.065 & 0.154 & 0.040 & -0.748 & 0.271 \\
\hline White collar workers & -1.036 & 0.034 & 0.230 & 0.022 & -0.993 & 0.245 \\
\hline Academics & -1.001 & 0.048 & 0.180 & 0.028 & -0.881 & 0.311 \\
\hline Others & -0.906 & 0.030 & 0.191 & 0.019 & -0.787 & 0.287 \\
\hline Self-employed & -0.600 & 0.079 & 0.146 & 0.057 & -0.303 & 0.506 \\
\hline Trade & -0.676 & 0.035 & 0.383 & 0.024 & -0.646 & 0.360 \\
\hline
\end{tabular}

Notes: The average effects in the last two columns are based on the parameters in Table 3 . The average in-treatment effect is evaluated at the average values of covariates at the beginning of supplementary UI benefit period for the group in the question. The average post-treatment effect is evaluated at the average values of covariates at the beginning of full-time unemployment after receipt of supplementary UI benefit. Coefficients in bold are statistically significant at the $5 \%$ level. 